\section{EVANESCENT-WAVE MICROSCOPY: PEEKING JUST UNDER THE SURFACE OF THE CELL Stephen W. Carmichael, ${ }^{1}$ Mayo Clinic}

There are many techniques available that enable us to know what is happening at the surface of a living cell. These techniques have allowed us to characterize many aspects of the process of exocytosis, the final cellular event in secretion. Patch clamping has given us quantitative measurements of the capacitance changes as the membrane of the secretory vesicle is added to the surface of the cell during exocytosis, and the change in the opposite direction as membrane is retrieved back into the cell during endocytosis. Tiny probes have measured electrochemical changes just outside the surface of the cell as reactive molecules are released into their surroundings. Differential interference contrast microscopy has given us high resolution pictures of the cell surface during exocytosis; real-time images are suggestive of bubbles breaking the surface of a boiling pot of water. However, exocytosis is known to be proceeded by an ordered series of events that occur below the surface of the cell. The secretory vesicles are products of the endoplasmic reticulum and Golgi apparatus. After they are formed, there is a maturation process, and then the vesicles apparently enter a "reserve" pool of mature vesicles. Unknown mechanisms take vesicles from the reserve pool and transfer them to the relatively small "readily-releasable" pool where they are primed for exocytosis. The readily-releasable pool can be quickly depleted, then the cell waits for vesicles to be moved up from the reserve pool.

These important last steps in secretion have been difficult to observe for a number of reasons. What we have needed is an optical tool that would allow us to peek just below the surface of a secretory cell. This much-needed tool appears to be evanescent-wave microscopy. As described by Martin Oheim, Dinah Loerke, Robert Chow, and Walter Stühmer, this clever utilization of optics promises to provide more information on exocytosis from neuroendocrine cells and neurons. ${ }^{2}$

The word evanescent means "rapidly fading," and it is the rapidly fading light at an interface between two media of higher and lower refractive indices. When light travels through a medium with a high refractive to an interface with a medium of lower refractive index, the light is refracted at the interface as the incident angle is moved from the perpendicular. When the incident angle is increased beyond the "critical angle," all of the light is reflected back into the medium of higher refractive index, a phenomenon called total internal reflection. This critical angle may be on the order of $60^{\circ}$ and $65^{\circ}$ (with $90^{\circ}$ being perpendicular to the surface). Evanescent waves are formed that penetrate only a fraction of the wavelength of light into the other medium. The optical properties are such that the intensity of the evanescent light at the surface can be 3 to 4 times the intensity of the incident light, but decays exponentially so that typically only a shallow volume $(80-300 \mathrm{~nm}$ from the surface) is illuminated.

In experiments described by Oheim et al., neuroendocrine cells from the adrenal medulla were grown on coverslips. The "footprint" where the cells were in contact with the glass was the interface surface. The volume just inside this surface was available for evanescent-wave microscopy. The chromaffin vesicles could be labeled with an acidophilic fluorescent dye (acridine orange) because the vesicle interior is at $\mathrm{pH} 5.5$ and selectively takes up the dye. By modifying a standard upright microscope, Oheim et al., could direct a laser beam to the glass/water interface, with the cells in the aqueous medium. With a hemicylindrical prism coupled to the glass (there is a "prismless" method, also, but it doesn't allow variations in the incident angle), a laser beam was directed at the specimen about $62^{\circ}$ from the perpendicular. They were able to determine that the evanescent wave penetrated about $260 \mathrm{~nm}$ into the cell.

Oheim et al., were able to visualize distinct fluorescing points that appeared to be chromaffin vesicles approaching the cell surface at relatively rapid rates, then seemingly stopped in a "docked" position. With stimulation, the fluorescence disappeared in a puff at the cell surface, evidence of exocytosis. It is clear that evanescent-wave microscopy has opened a window into how secretion progresses just below the surface of the cell. This technique allows for vesicles to be visualized and tracked quantitatively in three dimensions. Different biophysical properties can be described for vesicles in various functional states just beneath the surface of the cell. We are now equipped to answer important questions about the terminal events in vesicle trafficking. This new method of microscopy will be the wave of the future!

1. The author gratefully acknowledges Dr. Martin Oheim for reviewing this article.

2. Oheim, M., D. Loeke, R.H. Chow, and W. Stühmer, Evanest-wave microscopy: A new tool to gain insight into the control of transmitter release, Phil. Trans. $R$. Soc. Lond. B 354-307-318, 1999. See also: Steyer, J.A., H. Horstmann, and W. Almers, Transport, docking and exocytosis of single secretory granules in live chromaffin cells, Nature $388: 474-478,1997$. These two laboratories have led in the development of applying evanexcent-wave microscopy to studies of secretion.

\title{
INDEX OF ARTICLES
}

Evanescent-Wave Microscopy: Peeking Just Under ...............3

The Surface Of The Cell

Stephen W. Carmichael, Mayo Clinic

Clinical Laboratory Reagents: The Regulatory Hurdle.............8

Peter A. Takes, Stereotaxis

Correcting Scanning Errors in Scanning Probe Microscopes .10 Gregor Hsiao \& Jezz Leckenby, ThermoMicroscopes

NEW AND/OR INTERESTING AT M\&M '99........................ 14

Emission Myths ..........................................................20

Fred Schamber, R.J. Lee Instruments Company

Avoiding Etching of Silver When Using Silver Staining ..........22

With OsO4 Fixation

Rick Powell, Nanoprobes, Inc.

How to Calculate the Temperature Rise .............................24

Due to Beam Heating

William F. Tivol, Wadsworth Center

General Procedure for Antigen Retrieval Using ................ 28

Microwave Heating

M.A. Hayat, Kean University

Confocal Laser Scanning Microscopy

By Remote Access

H.H. Youngblum, J. Wilkinson, J.J. Youngblum

California State University

Combining FIB and Automated Microcleaving.................. 34

Provides Fast, Accurate Cross Sections

Janet Teshima (FEI Company) \& Efrat Rax (SELA USA)

A Personal View of the History of Twin-Jet Electropolisher 36

George Langford, Amenex Associates

Measuring Electron Intensities from Film......................... 38

Michael Lamvik

Alcohol, Acetone and Propylene Oxide as Dehydrating .... 40

Agents or Intermediate Solvents Prior to Epoxy Embedding

Of Biological Specimens

Hildegard $\mathrm{H}$. Crowley, University of Denver

Examining Ferromagnetic Samples in the SEM/EDX........ 41

Mary Mager, University of British Columbia

Comments: Which to Use, No. 1 or No.2 Cover Gasses.... 42

Thomas E. Philips, University of Missouri

Gary W. Gill, Laboratories, Inc.

MICROSCOPY 101 

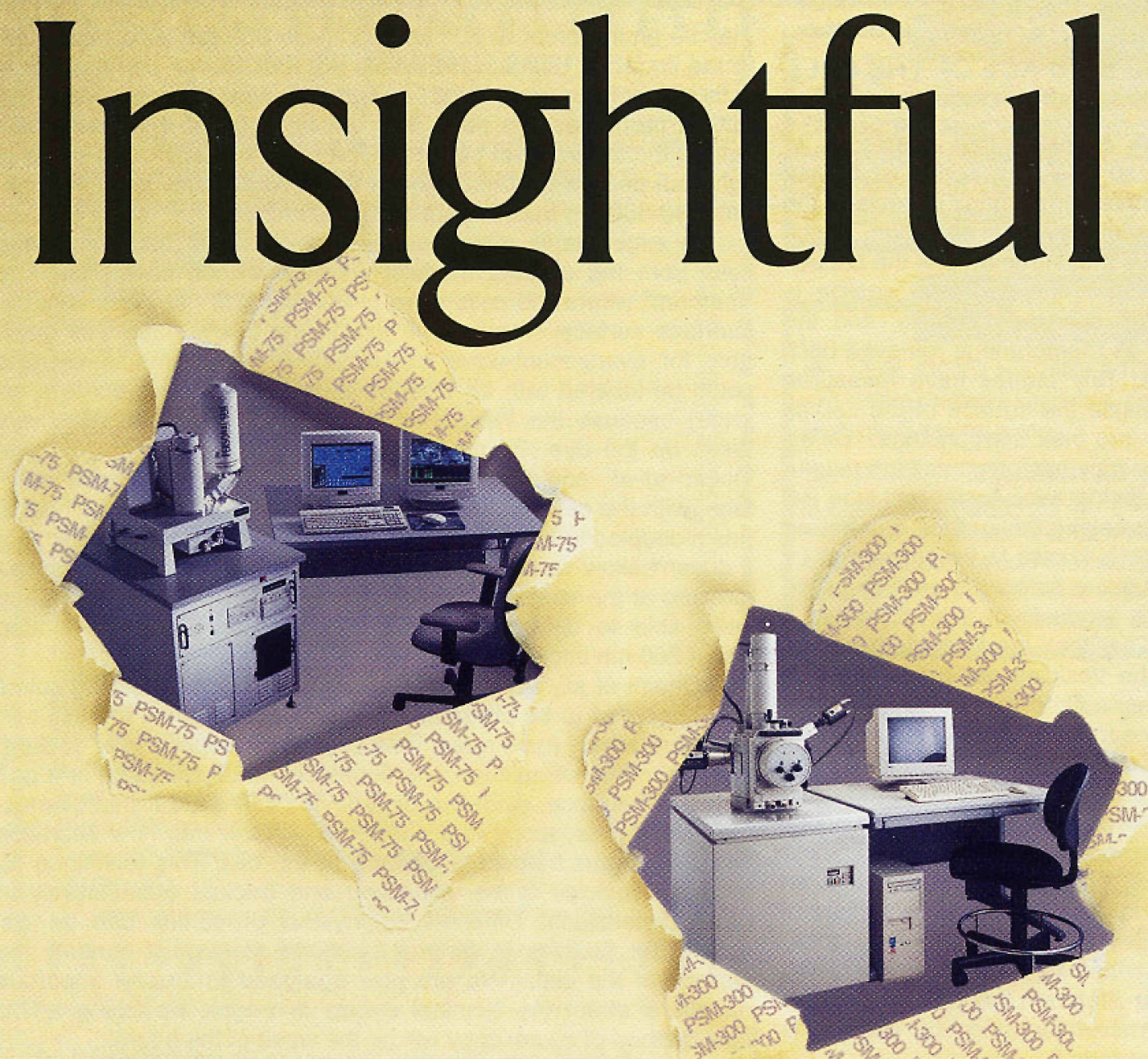

\section{The Right Tools for a Broad Spectrum of Applications}

Better insights, better analysis

Looking for better, more insightful analysis? Look no further. The PSM- 300 and the PSM-75 are simple-to-use analytical instruments that give you multiple, valuable insights related to your specific application. Better insights for a more comprehensive analysis. Better insights for critical information. Better insights to make the right decisions. Better insights for more effective solutions. Better insights to cost-saving solutions. And the list of insights goes on and on.

Customized for your specific application

The PSM- 300 or the PSM-75 can be easily customized to your specific application, some of which include:
- Automated Gun Shot Residue Analysis

- Automated Inclusion Analysis

- Automated Wear Debris Analysis

- Automated Particle Analysis

- Automated.Fiber Analysis

To get more insights into easy, more effective microanalysis at a truly affordable price call 1-800-538-6850.

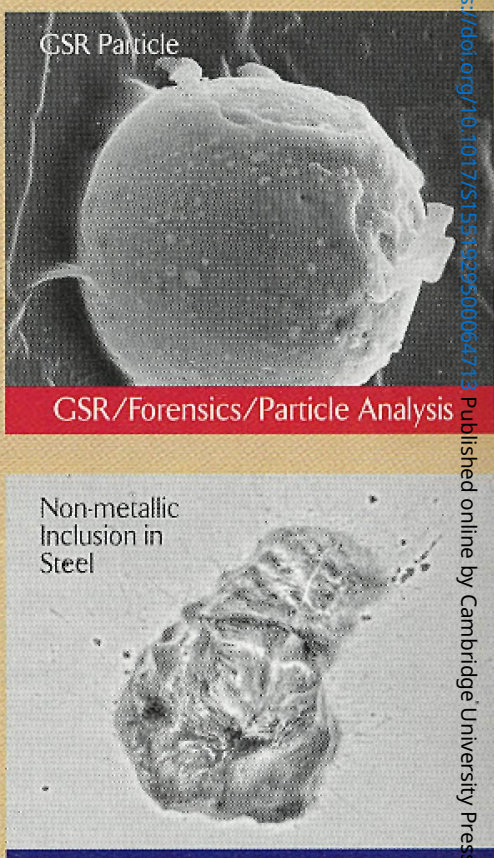

Metal Inclusion Analysis

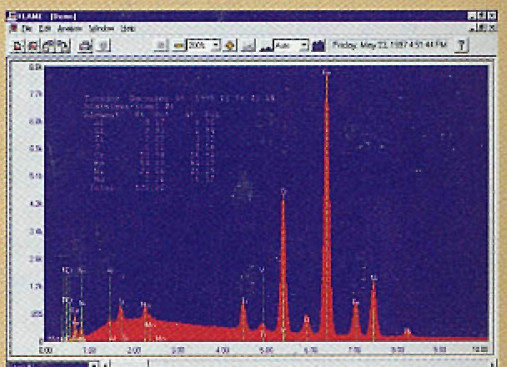

Inclusion EDX Spectrum

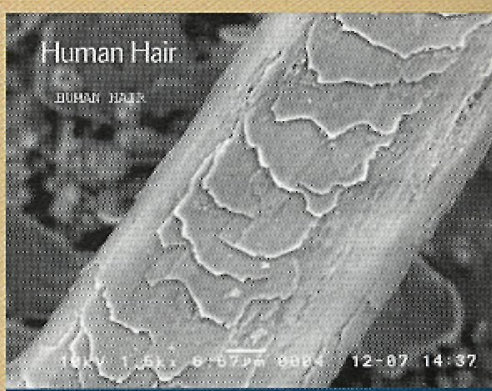

Forensics/Product Development

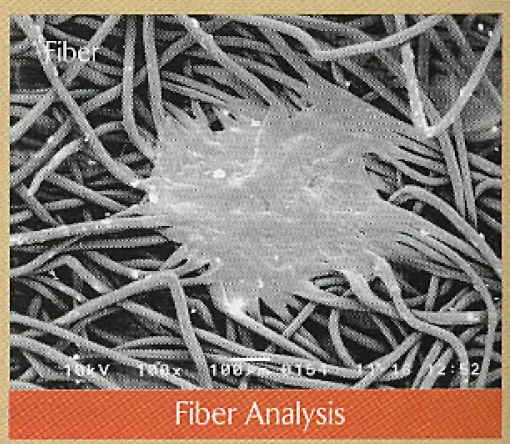
110000 


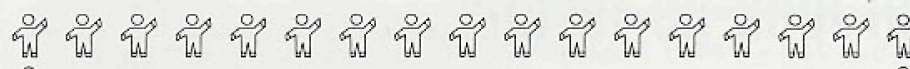
\% MICROSCOPY \& MICROANALYSIS '99 $\because$ An Editorial Comment

This happened to be the nineteenth EMSA/MSA MAS conference that I have attended-and it far outshined all others, in all categories!

There were a total of 2,901 participants, 1,866 being attendees and 1,035 being exhibitors. There were over 710 scientific papers presented. The attendance was some $25 \%$ over the previous year, and may well have been the largest in conference history.

Exhibitors advised that they were very pleased with the attendance-both in quantity and quality (meaning that many were purchasing!).

The Local Arrangements Committee did a truly outstanding job in organizing the affair. The highlight (at least for me) was the Sunday Evening Reception-held at the Portland Zoo. There were three separate serving areas, each with a different food type! No long waiting in lines to be served cafeteria style food! There were plenty of tables and chairs and the room to mill around and renew old acquaintances.

And at the conference even the coffee served was very, very good.

Credit for an outstanding meeting should also go to M\&M Meeting Management-Annamarie Dowling and her associates.

- - -Don Grimes, Editor

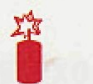

\section{is} 2

\section{话}
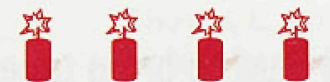

2000

MICROSCOPY SOCIETY OF AMERICA AWARDS
Distinguished Scientist Awards
(Physical \& Biological Sciences)
Burton Medal
Outstanding Technologist Awards
(Physical \& Biological Sciences)

Mort Maser Distinguished Service Award

All MSA Members are encouraged to nominate candidates for these Awards-to recognize our eminent Scientific and Society leaders. Deadline for the receipt of completed nominations is December 30, 1999.

Details available from the MSA Business Office:

MSA Business Office

435 North Michigan Ave. Ste. 1717

Chicago, IL 60611-4067

Tel.: (312)644-1527 Fax: (312)644-8557

eMail: BusinessOffice@MSA.Microscopy.Com $\rightarrow$ Dr. Robert Wick has joined NORAN Instruments as Director of Sales and will be responsible of their worldwide sales effort. Dr. Wick has over 15 years of experience in marketing and sales and has held senior positions at Carl Zeiss and Hamamatsu.

$\Rightarrow$ THE EIGHTEENTH ANNUAL SYMPOSIUM OF ADVANCES IN MICROSCOPY will be held on October 29-30, 1999 at the Coastline Convention Center, Wilmington, NC.

The Symposium, sponsored by the North Carolina Society for Microscopy and Microbeam Analysis, has been planned with the theme of "Nanoscopy" for the New Century?" Continuing with the tradition of the symposium, the guest lecturers are composed of both nationally and internationally distinguished scientists. The meeting has several purposes, not the least of which is to draw attention of the scientific community to emerging developments in the practical and basic research aspects of exciting new fields, and to bring people together from diverse disciplines to discuss how innovative techniques will be relevant to the future direction of microscopy and microprobe analysis. Special emphasis will be placed on how recent advances in nanoscience and nanoengineering have resulted in new knowledge that has benefited microscopy in general and are having a significant impact in the biological and physical sciences.

Three workshops will be offered: (a) Cryo-preparation Techniques, (b) Atomic Force Microscopy and (c) Digital Imaging Methods.

For further information, contact Ms. Betty Gooch: (919) 286-0411, email: b.gooch@cellbio.duke.edu

$\rightarrow$ A new Nanoindentation Web Site is intended to provide an overview of nanoindentation along with practical engineering and exciting materials science examples. Visit to learn about nanoindentatin with scanning probe microscopes: spm.aif.ncsu.edu/nanoindentation (no "www" required).

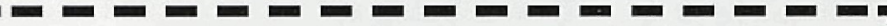

FRONT COVER IMAGE First Prize

For Fun Micrograph Contest Solder Joint Inspection

Cold flow 60/40 Tin Lead Solder on Copper Pad. Photograph combination using PaintShop Pro. Background image taken with AMRAY 1600 SEM. Contributed by: Jerry Long, Spokane Division of Hewlett-Packard

At the recent $\mathcal{M} \& \mathcal{M}$ ' 99 Conference in I Portland, we held our second "For Fun Micro- I I graph" contest. The contest was based on en- I I tries with two or more composite images, one | I of which must be microscopical in nature. I And we were delighted to receive a total of 27 entries! 


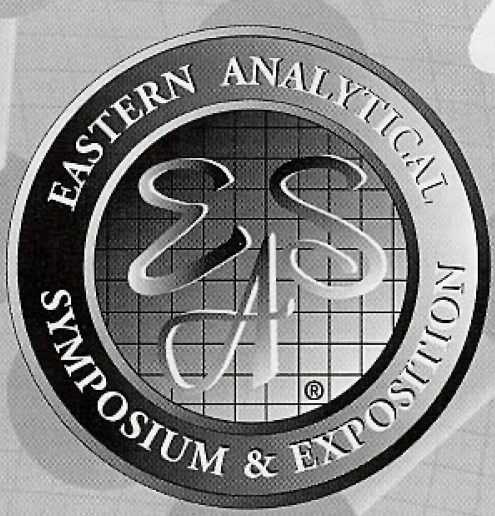

Then look no further...

\section{the place to enhance your}

\section{knowledge in the analytical and allied sciences is EAS!}

At the Eastern Analytical Symposium \& Exposition,

we take great pride in presenting an excellent

technical program, with over 600 invited and

contributed papers. The emphasis for presentations

is on cutting edge science and relates to real problems faced by scientists in all fields. EAS offers more than 80 workshops, seminars and short courses; featuring lectures, demonstrations, and/or hands-on experience presented by speakers from exhibiting companies.

We've worked hard to bring together over 235 exhibitors to provide scientists with a convenient single location to meet and discuss a vendor's product, new equipment, services, analytical techniques, and technologies.

Come to the Garden State Convention Center

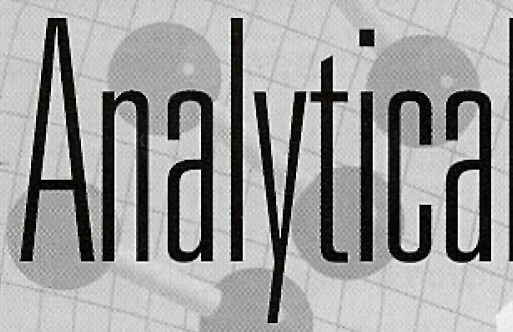
in Somerset, New Jersey on November 14-19,1999. Don't miss this incredible opportunity to be a part of the best Analytical Symposium \& Exposition ever!

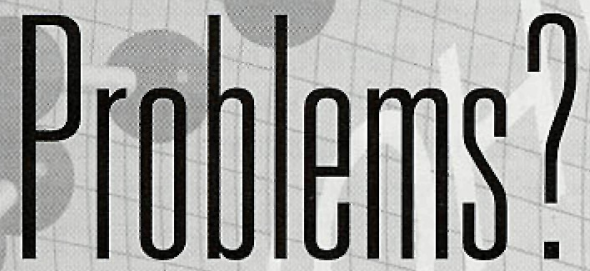

For more information visit

our EAS web site:

http://www.eas.org/ 
$\checkmark$ September 21/24 '99: Using Ultramicrotomy in Materials Science (Ventana/RMC) Tucson, AZ, Steve Miller: (520)903-9366

$\checkmark$ October 2 "99: 5th California Microscopy Colloquium. (CSU \& NCMS) San Francisco, CA. Http://online.sfsu.edu/-camicrol

$\checkmark$ October 6/14 '99: Optical Microscopy \& Imaging in the Biomedical Sciences (Marine Biological Lab) Wood Hole, MA. Carol Hamel: (508)289-7401, eMail: admissions@mbl.edu

$\checkmark$ October 20/22 "99: Asbestos Analysis by Transmission Electron Microscopy (McCrone Research Institute), Chicago, IL Nancy Daerr: (312)8427100, eMail: ndaerr@mcri.org

$\checkmark$ October 22 '99: 5th California Microscopy Colloquium (CA State Universities \& Northem CA Microscopy Society). San Farncisco State University. Http:/lonline.sfsu.edu/ camicrol

$\checkmark$ October 25/29 '99: American Vacuum Society's 46th International Symposium Seattle WA, Della Miller: (408)246-3600, fax: (408)246-7700

$\checkmark$ Nov 14/19 "99: 1999 Eastern Analytical Symposioum. Somerset, NJ.(302) 738-6218, eMail: easinfo@aol.com, http://www.eas.orgl

$\checkmark \quad$ Nov 15/18 '99: EuroFE '99. Toledo, Spain.

www.cmp-cientifica.com/EuroFE/schedule.htm

$\checkmark$ March 12/16 00: High Resolution Electron Microscopy in Materials Science Symposium (TMS Physical Metallurgy Committee) Nashville, TN, Diane Albert, Los Almos Natl Lab: (505)665-2266, Fax: (505)667-5268

$\checkmark$ April 3/4 "00: Microscopy of Composite Materials V (RMS \& Oxford Centre for Advanced Materials and Composites) St. John's College, Oxford, U.K.+44-1865248768, Fax: +44-1865-791237

$\checkmark$ April 11/13 '00: MICRO 2000 (Royal Microscopical Society) London www.rms.org.uk

$\checkmark$ May 9/12 '00: SCANNING 2000 San Antonio, TX., Mary K. Sullivan: (201) 818-1010, Fax: (201)818-0086, scanning@fams.org $\checkmark$ May 22/June 2 '00: PASEM 2000 (Univ. of Maryland) College Park, Md., Tim Maugel: (301)405-6898, tm11@umail.umd.edu

LEHIGH MICROSCOPY SCHOOLS

$\checkmark$ June 12/16 '00: SEM and X-ray Microanalysis

$\checkmark$ June 11 '00: Introduction to SEM and EDS

$\checkmark$ June 19/23 '00: Advanced Scanning Electron Microscopy

$\checkmark$ June 19/23 00: Quantitative X-ray Microanalysis

$\checkmark$ June 19/22 '00: Analytical Electron Microscopy

$\checkmark$ June 20/23 '00: Atomic Force Microscopy

$\checkmark$ June 19/23 '00: Microdiffraction

$\checkmark$ June 21/23 '00: Cryo SEM

For further information, contact Ms. Sharon Coe at Tel.: (610)758-5133 or by eMail at sharon.coe@lehigh.edu

$\checkmark$ June 26/30 '00: 7 th Asia-Pacific Conference on Electron Microscopy Singapore. eMail: micngml@nus.edu.sg or medlab2@nus.edu.sg http://www.med.nus.edu. sg/micsoc/7apem

$\checkmark$ July 8/13 '00: 2nd Meeting of the International Union of Microbeam Analysis Societies. Kailua-Kona, Hawaii. www. microanalysis. org/iumas2000/

$\checkmark$ July $9 / 14$ '00. 12th European Congress on Electron Microscopy. Bruno, Czech Republic. http://www.eurem2000. isibrno.cz/regform.html

$\checkmark$ August 13/17 '00: Microscopy \& Microanalysis '00: (MSA) Philadelphia, PA. Maryanne Rebedeau: (708)361-6166, mas@tradeshownet.com

$\checkmark$ September 3/8 '00: 11th International Congress of Histochemistry York, U. K., www.med.ic.ac.uk/external/ichc_2000

$\checkmark$ November 19/23 '00: First International Conference on Advanced Materials Processing Rotorua, New Zealand. Prof. Nigel Sammes: n.sammes@walkato.ac.nz

\section{Microscopy and Materials Science Series from Institute of Physics Publishing}

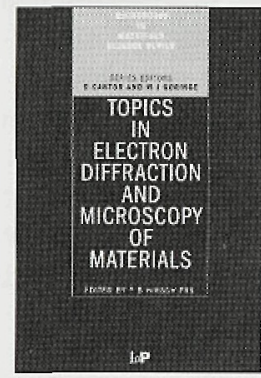

Topics in Electron Diffraction and Microscopy of Materials

Edited by Peter B Hirsch, FRS, University of Oxford, UK

Provides a useful overview of current applications for selected electron

microscope techniques which have become important and

widespread in their use for furthering our understanding of how

materials behave. It has been prepared to celebrate the retirement

of Professor Michael Whelan, who taught many of today's heads of

department, and was a pioneer in the development and use of

electron microscopy. Sir Peter Hirsch has edited the presentations made by Professor Whelan's

collaborators and colleagues, each one of whom has made important advances to the technique on which they write.

June 1999224 pages hardcover $075030538 \times \mathbf{E 7 5 . 0 0 / \$ 1 2 0 . 0 0}$

\section{The Measurement of Grain Boundary Geometry}

V Randle, University College of Swansea, UK

Provides a clear and comprehensive overview of the theory of grain boundary geometry, experimental aspects of data collection and data processing. Covers all aspects of electron optics techniques (SEM, TEM) to the study of grain boundaries in metals and alloys.

1993184 pages hardcover $0750302356 \mathbf{f 7 4 . 0 0 / \$ 1 4 7 . 0 0}$

\section{Electron Microscopy of Interfaces in Metals and Alloys}

C T Forwood and L M Clarebrough,

CSIRO Manufacturing Science and Technology, Australia

"... a book one can recommend to anybody working on interface and grain boundary structures The work treated is very impressive, well presented and perfectly illustrated ..."

Advanced Materials

1991436 pages hardcover $0750301163 \mathbf{E 1 0 5 . 0 0 / \$ 2 1 0 . 0 0}$

\section{Send your order to:}

USA/Canada - Orders (in US\$) to IOP Publishing, c/O AIDC, 2 Wintersport Lane, PO Box 20, Williston, Vermont 05495-0020. Tel: 1-800 6320880 (VT: 802862 0095) Fax: 8028647626

UK/Outside UK - Books Marketing, IOP Publishing Ltd., Dirac House, Temple Back, Bristol BS1 6BE, UK Tel: +44 (0) 1179297481 Fax: +44 (0) 1179294318

Please send a cheque made payable to IOP Publishing Ltd, or use your credit card Please send me

P\&P UK Add $£ 2.50+50 p$ for each additional book

USA Add $\$ 3.75+\$ 1.00$ for each additional book

ROW Add $£ 3.50+75 p$ for each additional book

I enclose a payment of $£$

Please charge my credit card $\square$ mc/Access $\square$ visa $\square$ American Express Card Number $\square \square \square \square \square \square \square \square \square \square \square \square \square \square \square \square$

Expiry Date

Name

Address

Signature

Institute of $\mathbf{P h y s i c s}_{\text {pubushing }}$ 